\title{
Antioxidant Capacity and Amino Acid Profiles of Egg Tofu
}

\author{
${ }^{1,2}$ Maizura Murad, ${ }^{1}$ Aminah Abdullah and ${ }^{1}$ Wan Aida Wan Mustapha \\ ${ }^{1}$ School of Chemical Sciences and Food Technology, Faculty of Science and Technology, \\ Universiti Kebangsaan Malaysia, 43600 Ukm Bangi, Selangor, Malaysia \\ ${ }^{2}$ School of Industrial Technology, Universiti Sains Malaysia, 11800 Penang, Malaysia
}

Received 2012-12-27, Revised 2013-02-26; Accepted 2013-09-06

\begin{abstract}
Tofu contains high quality protein source and antioxidant which could reduce risk of cancer. This research aims to determine the effect of soymilk and egg ratios on the antioxidant capacity, daidzein and genistein content and amino acid profiles of egg tofu. Egg tofu was prepared using soymilk and fresh egg in ratios of 1:1, 2:1, 3:1 and 4:1. Glucono-Delta-Lactone (GDL) was added in the egg tofu to act as a coagulating agent. Increased of soymilk at all ratios had significantly $(\mathrm{p}<0.05)$ increased in Ferric-Reducing Antioxidant Power (FRAP), daidzein and genistein content of egg tofu. Conversely, decreased in soymilk ratio had significantly $(\mathrm{p}<0.05)$ increased the radical scavenging activities of the 2,2-Azino-Bis 3-ethylbenzothiazoline-6-Sulfonic acid (ABTS) and 2,2Diphenyl-2-Picrylhydrazyl (DPPH) in egg tofu. Increased of soymilk ratio up to 3:1 caused decreased in amino acid methionine (met) and cystein (cys) significantly $(p<0.05)$. A significant $(p<0.01)$ and a positive correlation was observed between Total Phenolic Content (TPC) and FRAP $(r=0.93)$. However, there was a negative $(\mathrm{p}<0.01)$ correlation between TPC and DPPH $(\mathrm{r}=-0.83)$. The antioxidant capacity of egg tofu in DPPH assay showed a positive and significant $(\mathrm{p}<0.01)$ correlation with cysteine, methionine and tryptophan with $r$ value of $0.92,0.93$ and 0.96 respectively. Higher content of egg in egg tofu had contributed to the increased of antioxidant capacity as indicated in DPPH assay and ABTS assay as well as amino acid methionine and cysteine.
\end{abstract}

Keywords: Daidzein, Antioxidant Capacity, Egg Tofu, Genistein, Amino Acid Profiles

\section{INTRODUCTION}

Antioxidants help to protect cells, DNA, lipids and proteins from the damaging effects of prooxidation or free radicals primarily derived from oxygen Reactive Oxygen Species (ROS) by inhibiting the oxidation via preventing the propagation of oxidizing chain reactions (Bouayed and Bohn, 2010). Currently, consumers are conscious of healthy diet and more attention is given on functional foods and ingredients that provide basic nutrition as well as bioactive compounds that contribute to the total antioxidant capacity of food (Medoua et al., 2009). This trend is further strengthened by previous research which suggested that, diets rich in antioxidants play a critical role in human health and disease such as lower risk of cancer and cardiovascular disease (Bouayed and Bohn, 2010).

Soybean (Glycine max L.) has been recognized as a health promoting food. It contains a large amount of macronutrient such as protein (40\%) and lipid (20\%) and also rich in polyphenolic compounds namely isoflavones (Shao et al., 2009). Twelve isoflavones have been reported in soybean, however genistein and daidzein are found to be dominant and perform as important antioxidant properties (Dwiecki et al., 2009). In addition, soybean also contains phenolic compounds such as ferulic acid, chlorogenic acid, gallic acid, vanilic acid and syringic acid that exhibited antioxidant activities (Duenas et al., 2012; Tyug et al., 2010).

Corresponding Author: Aminah Abdullah, School of Chemical Sciences and Food Technology, Faculty of Science and Technology, Universiti Kebangsaan Malaysia, 43600 Ukm Bangi, Selangor, Malaysia 
Eggs are an affordable source of vital nutrients and it is commonly used in food industries due to its excellent functionality for industrial applications (Walker et al., 2012). Triacylglycerols, phospholipids, protein and carbohydrates in egg yolk serves as an excellent food emulsifier (Daimer and Kulozik, 2009), while ovalbumin in egg white is a good gelling and a foaming agent (Arzeni et al., 2012). Moreover, egg yolk (Nimalaratne et al., 2011) and egg white (You et al., 2010) contain amino acids that contributed to the antioxidant activities.

Egg tofu has a less beany flavor compared to the regular soy tofu and it contains high protein. Egg tofu has a smooth texture and it is generally packed in a plastic tube. Commercial egg tofu contains whole egg, soy powder or soymilk or soy seasoning and GluconoDelta-Lactone (GDL). Currently no literature is available on the antioxidant capacity and amino acid profile of egg tofu formulated with different ratios of soymilk and egg. Therefore, the objective of this research were to determine the effect of soymilk and egg ratios on the total phenolic content, antioxidant capacity, daidzein and genistein content and amino acids profile of egg tofu.

\section{MATERIALS AND METHODS}

\subsection{Chemicals}

Soybeans and Glucono-Delta-Lacton (GDL) were obtained from Bakery products supplier (Yummy's Bakery Sdn. Bhd. Selangor, Malaysia) and egg (grade A) was obtained from local supermarket (Giant, Bangi, Selangor). Folin-Ciocalteu's (FC) reagent was obtained from Merck (Darmstadt, Germany). Sodium carbonate, gallic acid, 2,2-diphenyl-1-picrylhydrazyl (DPPH), 2,4,6,Tris (1-pyridyl)-5-triazine (TPTZ) and 2,2'-azino-bis 3ethylbenzothiazoline-6-sulfonic acid (ABTS) were purchased from Sigma (Steinheim, Germany) and ferrous sulphate was obtained from R\&M Chemicals (Essex, UK).

\subsection{Preparation of Egg Tofu}

Soybeans $(100 \mathrm{~g})$ were soaked in water, rinsed and ground using commercial blender (WARING 240v Torrington, C.T, USA). A soybean: water ratio of $1: 3$ was used. The mixture was blended at high speed for 1 min and filtered with muslin cloth. The slurry was cooked at $100^{\circ} \mathrm{C}$ for $15 \mathrm{~min}$. Egg tofu was prepared from a mixture of soymilk and fresh egg at ratios of $1: 1,2: 1$, $3: 1$ and $4: 1$ and GDL $(0.4 \% \mathrm{w} / \mathrm{w})$ was added to the mixture and mix well. The mixture $(50 \mathrm{~g})$ was poured into a $100 \mathrm{ml}$ round polypropylene microwaveable container with lid (55 mm diameter $\times 40 \mathrm{~mm}$ high) and steamed at $90^{\circ} \mathrm{C}$ for $20 \mathrm{~min}$. Samples were cooled to room temperature and stored at $-4^{\circ} \mathrm{C}$ until analysis.

\subsection{Determination of Moisture, Fat and Protein Content}

The moisture, fat and protein content of egg tofu were determined using AOAC (2000) method. For moisture content analysis, $5 \mathrm{~g}$ sample was weighed and dried in an oven at $105^{\circ} \mathrm{C}$ until constant weight. Protein content was determined using Kjeldhal method and fat content was determined by soxhlet extraction using Soxtec System HT1043 Extractor unit. All samples were measured in three replicates.

\subsection{Sample Extraction}

Egg tofu was freeze dried and ground using commercial blender (WARING 240v Torrington, C.T, USA) at high speed for $2 \mathrm{~min}$, filtered using stainless steel sieve (40 mesh grid), kept in air tight bottles and stored at $-20^{\circ} \mathrm{C}$. The sample was extracted according to the method of Kim and Lee (2000) with some modifications. Ten grams of sample were extracted with $100 \mathrm{~mL}$ of $80 \%$ methanol and was sonicated for $20 \mathrm{~min}$. The sample was filtered using filter paper (Sartorius grade 292) and rinsed with $50 \mathrm{~mL} 100 \%$ methanol. The residue was re-extracted with $50 \mathrm{~mL}$ of $80 \%$ methanol and the solvent was evaporated at $50^{\circ} \mathrm{C}$ for $24 \mathrm{hrs}$. Subsequently, sample was dissolved in $50 \mathrm{~mL} 100 \%$ methanol and made up to volume $(100 \mathrm{ml})$ with dionized water. The mixture was centrifuged (Hermle $\mathrm{GmbH}$, Germany) at $10000 \mathrm{rpm}$ for $15 \mathrm{~min}$ and the supernatant was stored at $-20^{\circ} \mathrm{C}$ before analyzed for total phenolic content (TPC), Ferric Reducing/Antioxidant Power (FRAP) and radical scavenging activities of the 2,2'azino-bis3-ethylbenzothiazoline-6-sulfonic acid (ABTS) and 2,2-Diphenyl-1-Picrylhydrazyl (DPPH).

\subsection{Determination of Total Phenolic Content (TPC)}

Total phenolic content of sample extracts was determined using Folin-Ciocalteu reagent as described by Singleton and Rossi (1965) and Song et al. (2010) One $\mathrm{ml}$ of the sample was thoroughly mixed with $5 \mathrm{ml}$ Folin-Ciocalteu reagent. After $5 \mathrm{~min}, 4 \mathrm{~mL}$ of $7.5 \%$ sodium carbonate $\left(\mathrm{Na}_{2} \mathrm{CO}_{3}\right)$ was added to the mixture and allowed to react for $2 \mathrm{hr}$ at room temperature in the dark. The absorbance was measured at $765 \mathrm{~nm}$ using a microplate reader spectrophotometer $(\mathrm{EPOCH}$ Microplate Spectrophotometer, Vermont, USA). The 
standard curve of gallic acid solutions (20, 40, 60, 80 and $100 \mathrm{mg} \mathrm{L}^{-1}$ ) was prepared using a similar procedure. All samples were measured in three replicates and the results were expressed as $\mathrm{mg}$ GAE/100 g dry weight.

\subsection{Antioxidant Capacity}

\subsubsection{Determination of Ferric Reducing/Antioxidant Power (FRAP) Assay}

The FRAP assay was carried out according to the method of Benzie and Strain (1996). FRAP reagent was prepared from acetate buffer (pH 3.6), $10 \mathrm{mM}$ TPTZ diluted with $40 \mathrm{mM} \mathrm{HCl}$ and $20 \mathrm{mM}$ iron (III) chloride solution in proportion of 10:1:1 (v/v) respectively. The FRAP reagent was prepared fresh and was warmed to $37^{\circ} \mathrm{C}$ in the oven prior to use. $50 \mu \mathrm{L}$ of sample extracts were added to $1.5 \mathrm{~mL}$ of the FRAP reagent and mixed well. The absorbance was measured at $593 \mathrm{~nm}$ using a microplate reader spectrophotometer (EPOCH Microplate Spectrophotometer, Vermont, USA) after 4 min. The standard curve of iron (II) sulfate solutions (200, 400, 600, 800 and $1000 \mathrm{mg} \mathrm{L}^{-1}$ ) was prepared using the similar procedure and all samples were measured in three replicates. Results were expressed as $\mu \mathrm{mol} \mathrm{Fe}(\mathrm{II}) / 100 \mathrm{~g}$ dry weight.

\subsection{Determination of 2,2'-Azino-Bis 3- Ethylbenzothiazoline-6-Sulfonic (ABTS) Assay}

The ABTS radical scavenging activity was determined according to the method of Binsan et al. (2008) with some modifications. The radical scavenging activity of ABTS radical cations $\left(\mathrm{ABTS}^{+}\right.$) was based on the reduction of $\mathrm{ABTS}^{+}$by antioxidants present in the sample extracts. The stock solution was prepared by mixing $7 \mathrm{mM}$ ABTS solution and $2.45 \mathrm{mM}$ potassium persulphate solution in equal quantities and allowed to react for $16 \mathrm{hr}$ at room temperature in the dark. The solution was diluted with methanol in order to obtain an absorbance of 0.7 at $734 \mathrm{~nm}$ using a microplate reader spectrophotometer (EPOCH Microplate Spectrophotometer, Vermont, USA). For reaction process, $100 \mu \mathrm{L}$ samples were mixed with $1000 \mu \mathrm{L}$ ABTS solution and the mixture was allowed to react at room temperature for $10 \mathrm{~min}$ in the dark. The declined in absorbance was measured at $734 \mathrm{~nm}$ using a microplate reader spectrophotometer. A standard curve was prepared using Trolox ranging from 5 to $300 \mu \mathrm{M}$. Samples were measured in three replicates and the results were expressed as $\mu \mathrm{mol} \mathrm{TE} / 100 \mathrm{~g}$ dry weight.

\subsection{Determination of 2,2-Diphenyl-1- Picrylhydrazyl (DPPH) Assay}

The radical scavenging activity of DPPH was determined based on the method described by Akowuah et al. (2005) and Tang et al. (2013). In this method $200 \mu \mathrm{L}$ of $0.1 \mathrm{mM}$ DPPH methanolic solution was added into $20 \mu \mathrm{L}$ of sample extracts and mixed with $80 \mu \mathrm{L}$ of methanol. The mixture was allowed to react at room temperature in the dark for $1 \mathrm{~h}$. The control was prepared by mixing $2 \mathrm{~mL}$ of DPPH and $1 \mathrm{~mL}$ of methanol. The absorbance was measured at $517 \mathrm{~nm}$ using a microplate reader spectrophotometer (EPOCH Microplate Spectrophotometer, Vermont, USA). Samples were measured in three replicates and scavenging activity of DPPH was calculated as \% inhibition of DPPH $=[$ Abs control-Abs sample/Abs control] $\times 100$.

\subsection{Determination of Daidzein and Genistein Content}

Analysis of daidzein and genistein content in sample extracts were determined according to the method of Hasnah et al. (2009) with some modifications. All samples were freeze dried and ground into small particles. Approximately $1 \mathrm{~g}$ of dried sample was extracted with $10 \mathrm{~mL}$ of $2 \mathrm{M} \mathrm{HCl}$ and $40 \mathrm{~mL}$ of $96 \%$ ethanol and sonicated for $20 \mathrm{~min}$. Samples were then refluxed in water bath at $100^{\circ} \mathrm{C}$ for $4 \mathrm{hr}$ and made up to volume $(50 \mathrm{~mL})$ with $96 \%$ ethanol. The mixture was adjusted to $\mathrm{pH} 4.0$ with $\mathrm{NaOH}$ and centrifuged at 4000 rpm for $20 \mathrm{~min}$. The supernatant was filtered through filter paper (Sartorius grade 292) and followed with 0.20 $\mathrm{mm}$ polytetrafluoroethylene microfilter before inject into High Performance Liquid Chromatography (HPLC) (Shimadzu, Kyoto, Japan). The series of standard curve of genistein and daidzein ranging from 15 to $50 \mu \mathrm{M}$ and from 10 to $35 \mu \mathrm{M}$ respectively were prepared. Individual standard solutions of genistein and daidzein were prepared by dissolving with $2 \mathrm{~mL}$ of Dimethylsulphoxide (DMSO) and made up to volume (100 mL) with $96 \%$ of ethanol. Column C18 Symmetry Shield 18.3 .5 um $(3.9 \times 150 \mathrm{~mm})$ from Waters (Ireland) was used. The mobile phase used was acetonitrile-water $(1: 2 \mathrm{v} / \mathrm{v})$ and the flow rate was set at $0.8 \mathrm{~mL} / \mathrm{min} .20 \mu \mathrm{L}$ samples were injected into the column at $40^{\circ} \mathrm{C}$. The component detection was performed by a Photodiode Array (PDA) detector at a wavelength of $254 \mathrm{~nm}$.

\subsection{Determination of Amino Acids Profile 2.10.1. Acid Hydrolysis}

Analysis of the amino acids namely aspartic Acid (Asp), Threonine (Thr), Serine (Ser), Glutamic acid 
(Glu), Proline (Pro), Glycine (Gly), Alanine (Ala), Valine (Val), Isoleucine (Ile), Leucine (Leu), Tyrosine (Tyr), Phenylalanine (Phe), Histidine (His), lysine (ys) and Arginine (Arg) were determined through acid hydrolysis according to the methods of WCD (1993). Approximately $0.3 \mathrm{~g}$ of sample was weight into a glassstoppered test tube and hydrolyzed with $5 \mathrm{~mL}$ of $6 \mathrm{~N} \mathrm{HCl}$ at $110^{\circ} \mathrm{C}$ for $24 \mathrm{~h}$. Samples were cool to room temperature before it was filtered through filter paper (Sartorius grade 292) into $100 \mathrm{~mL}$ volumetric flask. The internal standard $(400 \mu \mathrm{L})\left(50 \mu \mathrm{moL} \mathrm{mL} \mathrm{m}^{-1} \alpha\right.$-Aminobutyric Acid (AABA) in $0.1 \mathrm{M} \mathrm{HCl}$ ) was added and made up to $100 \mathrm{~mL}$ with distilled water. The aliquot was filtered through $0.20 \mathrm{~mm}$ polytetrafluoroethylene microfilter.

As for derivatization, $10 \mu \mathrm{L}$ of filtered hydrolysated samples or standard were transferred into a $1.5 \mathrm{~mL}$ glass vial and $70 \mu \mathrm{L}$ of borate buffer solution was added and mix well. Then, $20 \mu \mathrm{L}$ of AccQ Flour reagent $(3 \mathrm{mg}$ $\mathrm{mL}^{-1}$ in acetonitrile) was added to the mixture and thoroughly mix through vortex for several seconds. Ten microliter of samples and standards were injected into the HPLC (Waters 2475, Waters Co., Milford, MA, USA) and the flow rate was set at $1 \mathrm{~mL} \mathrm{~min}^{-1}$. Analysis of the amino acids was performed with AccQ Tag $(3.9 \times 150 \mathrm{~mm})$ column. The mobile phase A was Eluent A (200 mL AccQ Tag to $2 \mathrm{~L}$ of Milli-Q water) and mobile phase B, was Eluent B (60\% acetonitrile). The linear gradient condition was set as follows: $100 \% \mathrm{~A}$ and $0 \% \mathrm{~B}$ at start, $98 \% \mathrm{~A}$ and $2 \% \mathrm{~B}$ at $0.5 \mathrm{~min}, 91 \% \mathrm{~A}$ and $9 \% \mathrm{~B}$ at $15 \mathrm{~min}, 87 \% \mathrm{~A}$ and $13 \% \mathrm{~B}$ at $19 \mathrm{~min}, 65 \% \mathrm{~A}$ and $35 \% \mathrm{~B}$ at $32 \mathrm{~min}, 65 \% \mathrm{~A}$ and $35 \% \mathrm{~B}$ at $34 \mathrm{~min}, 0 \%$ $\mathrm{A}$ and $100 \% \mathrm{~B}$ at $35 \mathrm{~min}, 0 \% \mathrm{~A}$ and $100 \% \mathrm{~B}$ at $38 \mathrm{~min}$, $100 \% \mathrm{~A}$ and $0 \% \mathrm{~B}$ at $39 \mathrm{~min}$ and $100 \% \mathrm{~A}$ and $0 \% \mathrm{~B}$ at $50 \mathrm{~min}$. Detection was carried out by a fluorescence detector ( $\lambda$ excitation and $\lambda$ emission at $250 \mathrm{~nm}$ ).

\subsection{Performic Oxidation}

Amino acids such as Cystein (Cys) and Methionine (Met) were determined through performic oxidation. Approximately $0.3 \mathrm{~g}$ of sample was weighed into a glassstoppered test tube and $2 \mathrm{~mL}$ fresh chilled performic acid (formic acid: hydrogen peroxide, 9:1 v/v) was added. The tube was kept in box with ice cubes at $4^{\circ} \mathrm{C}$ for $16 \mathrm{~h}$. Then, $0.4 \mathrm{~mL}$ of Hydrogen Bromide (HBr) was added and allowed to react at $4^{\circ} \mathrm{C}$ for $30 \mathrm{~min}$. Sample was dried to remove performic acid using water bath and proceed with $6 \mathrm{~N} \mathrm{HCl} \mathrm{hydrolysis} \mathrm{as} \mathrm{mention} \mathrm{above.} \mathrm{Standard}$ solutions were prepared by mixing $5 \mathrm{~mL}$ of AABA $(50$ $\left.\mu \mathrm{moL} \mathrm{mL}^{-1}\right), 10 \mathrm{~mL}$ of Cysteic acid $\left(25 \mu \mathrm{moL} \mathrm{mL}{ }^{-1}\right)$ and $10 \mathrm{~mL}$ of methionine $\left(25 \mu \mathrm{moL} \mathrm{mL}^{-1}\right)$ and made up to volume $(100 \mathrm{~mL})$ with $0.1 \mathrm{~N} \mathrm{HCl}$ (solution $\mathrm{A}$ ). Then $1.5 \mathrm{~mL}$ of solution A was mixed with $1.5 \mathrm{ml}$ of amino acid standard H "pierce" (Pierce Chemical Co. Rockford IL, USA) (solution B). $160 \mu \mathrm{L}$ of solution B was mixed with $840 \mu \mathrm{L}$ distilled water and the total volume was 1 $\mathrm{mL}$. Derivatization process was executed as explained in the acid hydrolysis section prior to injection into HPLC (Waters 2475, Waters Co., Milford, MA, USA).

\subsection{Alkaline Hydrolysis}

Tryptophan (Trp) was determined through alkaline hydrolysis. Approximately $0.3 \mathrm{~g}$ of sample was weighed into a glass-stoppered test tube and mixed with $15 \mathrm{~mL}$ of fresh $4.3 \mathrm{~N}$ lithium oxide $\left(\mathrm{LiOH} \mathrm{H}_{2} \mathrm{O}\right)$. The mixture was flushed with nitrogen gas prior to heat at $120^{\circ} \mathrm{C}$ for $16 \mathrm{~h}$. The hydrolysate was transferred into a beaker containing $50 \mathrm{~mL}$ distilled water and $9 \mathrm{~mL}$ of $6 \mathrm{~N} \mathrm{HCl}$. The $\mathrm{pH}$ was adjusted to 4.5 with diluted $\mathrm{HCl}$. The aliquot was filtered through filter paper (Sartorius grade 292) and diluted with distilled water to volume of $100 \mathrm{~mL}$ in volumetric flask. Standard solutions were prepared by dissolving $0.05 \mathrm{~g}$ of tryptophan with $0.1 \mathrm{~N} \mathrm{HCl}$ in $50 \mathrm{~mL}$ volumetric flask and mixed thoroughly until completely dissolved. The solution $(50 \mu \mathrm{L})$ was pipetted in $10 \mathrm{~mL}$ volumetric flask and made up to volume with mobile phase. Sample and standard were filtered through $0.20 \mathrm{~mm}$ polytetrafluoroethylene microfilter and $10 \mu \mathrm{L}$ was injected into the HPLC (Waters 2475, Waters Co., Milford, MA, USA). Analysis of the tryptophan was performed with a Nova Pak C18, $(3.9 \times 150$ $\mathrm{mm})$ column. The mobile phase used was $0.0085 \mathrm{M}$ sodium acetate at $\mathrm{pH} 4.0$ and methanol at a ratio of 86.7 : 13.3 and the flow rate was $1.5 \mathrm{~mL} \mathrm{~min}^{-1}$. Detection was carried out by fluorescence detector ( $\lambda$ excitation at 285 $\mathrm{nm}$ and $\lambda$ emission at $345 \mathrm{~nm}$ ).

\subsection{Statistical Analysis}

Data was analyzed using Excel (Microsoft Inc.,) and Statistical Package for Social Science (SPSS version 15.0) software. Significant differences between samples were analyzed using Analysis of Variance (ANOVA) and Duncan's multiple-range test $(\mathrm{p}<0.05)$. Pearson's correlation coefficient (r) was used to determine the correlation between the data of total phenolic content, antioxidant capacity, daidzein, genistein and amino acids.

\section{RESULTS}

\subsection{Moisture, Fat and Protein Content in Egg Tofu}

The effects of soymilk and egg at different ratios on moisture, fat and protein content in egg tofu are presented in Table 1. The moisture content of egg tofu increased as the soymilk content increased up to a ratio of $3: 1$. Egg tofu 
with higher moisture content, which is more than $87.6 \%$, resulted in a very soft and fragile texture. An increased in soymilk content had significantly $(\mathrm{p}<0.05)$ decreased the fat and protein content in egg tofu.

\subsection{Total Phenolic Content and Antioxidant Capacity of Egg Tofu}

The effect of egg and soymilk ratios on the total phenolic content of egg tofu is presented in Fig. 1. The total phenolic content increased significantly $(p<0.05)$ for egg tofu with higher ratio $(4: 1)$ of soymilk which was $118.9 \mathrm{mg} \mathrm{GAE} / 100 \mathrm{~g}$ dry weight sample. However, there was no significant $(\mathrm{p}>0.05)$ different in TPC for soymilk and egg ratios of $1: 1,2: 1$ and $3: 1$.

The antioxidant capacity of egg tofu were determined based on the ability of the antioxidant to reduce ferric iron $\left(\mathrm{Fe}^{3+}\right)$ to ferrous $\left(\mathrm{Fe}^{2+)}\right.$ in the FRAP reagent and form a blue products namely ferrous-TPTZ complex (Benzie and Strain, 1996). Figure 2 shows the effect of soymilk and egg ratios on Ferric Reducing Antioxidant Power (FRAP) of egg tofu. The FRAP value of egg tofu at soymilk and egg ratios $1: 1,2: 1,3: 1$ and $4: 1$ was 1101.6, 1137.6, 1276.8 dan 1677.6 $\mu \mathrm{moL} \mathrm{Fe}$ (II)/100 g dry weight respectively.

Effect of soymilk and egg ratios on the radical scavenging activity of 2,2'-azino-bis3-ethylbenzothiazoline6-sulfonic acid (ABTS) of egg tofu is shown in Fig. 3. In ABTS assay, the antioxidant capacity of egg tofu at soymilk and egg ratios $1: 1,2: 1,3: 1$ and $4: 1$ was $243.3,206.7,173.3$ and $176.7 \mu \mathrm{moL}$ TE/100 g dry weight respectively.

The antioxidant capacity of egg tofu was also determined through scavenging activity of 2,2-Difenil-1Pikrilhidrazil (DPPH) and the results was expressed as percentage of DPPH inhibition. Effect of soymilk and egg ratios on radical scavenging activity of DPPH of egg tofu is shown in Fig. 4. Increased in soymilk content had significantly $(\mathrm{p}<0.05)$ decreased the DPPH inhibition at all soymilk and egg ratios of 1:1 (24.1\%), 2:1 (21.9\%), $3: 1(20.7 \%)$ and $4: 1(17.2 \%)$.

\subsection{Daidzein and Genistein Content of Egg Tofu}

The effect of soy milk and egg ratios on daidzein and genistein content of egg tofu are shown in Table 2. Daidzein and genistein content increased significantly $(\mathrm{p}<0.05)$ as soymilk content increased at all ratios. Results clearly showed that soymilk had contributed to the higher daidzein and genistein content in egg tofu.

\subsection{Amino Acid Profiles of Egg Tofu}

Egg and soybean are an excellent source of protein and possess high quality and quantity of amino acids (Dia et al., 2009; Rock et al., 2013). Table 3 shows the effect of soymilk and egg ratios on the amino acids profiles of egg tofu. Egg tofu contains all the essential amino acids such as phenylalanine (phe), isoleucine (ile), leucine (leu), lysine (lys), Tyrosine (Tyr), Threonine (Thr), Valine (Val), tryptophan (trp), cystein (cys) and methionine (met). Increased in soymilk ratio up to $3: 1$ had significantly $(\mathrm{p}<0.05)$ decreased amino acids methionine (met) and cysteine (cys) in egg tofu.

Table 1. Effects of soy milk and egg ratios on the moisture, fat and protein content of egg tofu

\begin{tabular}{llll}
\hline $\begin{array}{l}\text { Soy milk: } \\
\text { Egg ratio }\end{array}$ & $\begin{array}{l}\text { Moisture } \\
(\%)\end{array}$ & $\begin{array}{l}\text { Fat } \\
(\%)\end{array}$ & $\begin{array}{l}\text { Protein } \\
(\%)\end{array}$ \\
\hline $1: 1$ & $84.2 \pm 0.1^{\mathrm{c}}$ & $5.4 \pm 0.2^{\mathrm{a}}$ & $8.3 \pm 0.1^{\mathrm{a}}$ \\
$2: 1$ & $87.6 \pm 0.1^{\mathrm{b}}$ & $4.0 \pm 0.2^{\mathrm{b}}$ & $6.6 \pm 0.1^{\mathrm{b}}$ \\
$3: 1$ & $89.6 \pm 0.1^{\mathrm{a}}$ & $3.2 \pm 0.1^{\mathrm{c}}$ & $5.8 \pm 0.5^{\mathrm{c}}$ \\
$4: 1$ & $89.9 \pm 1.0^{\mathrm{a}}$ & $2.9 \pm 0.3^{\mathrm{c}}$ & $5.6 \pm 0.8^{\mathrm{c}}$ \\
\hline
\end{tabular}

a-c Mean value \pm standard deviation $(\mathrm{n}=3)$ in a column followed by different superscript letters are significantly different $(\mathrm{p}<0.05)$

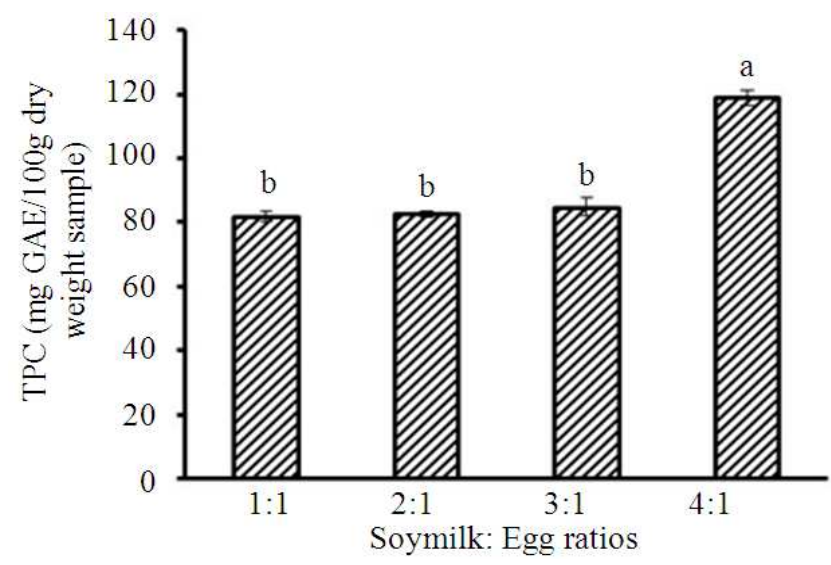

Fig. 1. Effect of soymilk and egg ratios on the Total Phenolic Content (TPC) of egg tofu. Bars are the standard deviations of the means $(n=3)$ and different letters are significantly different $(\mathrm{p}<0.05)$ 


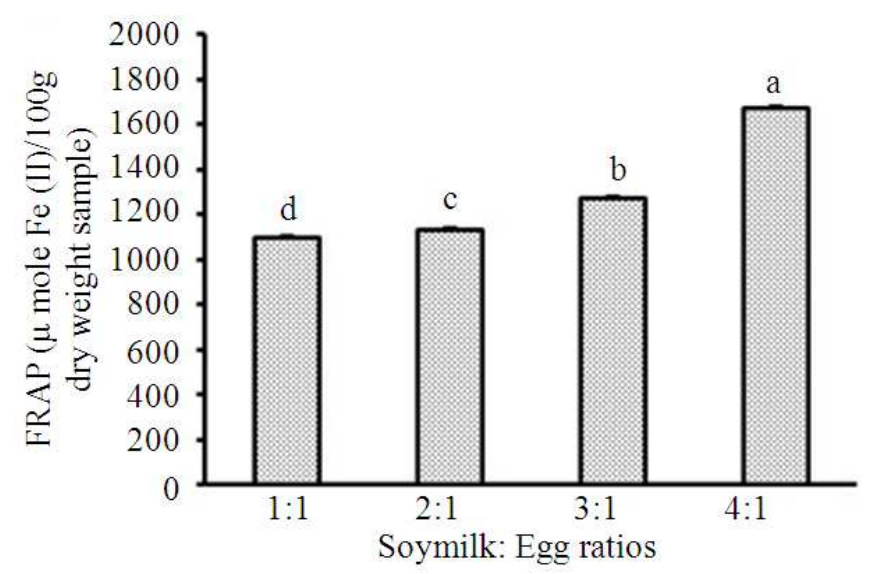

Fig. 2. Effect of soymilk and egg ratios on the Ferric Reducing Antioxidant Power (FRAP) of egg tofu. Bars are the standard deviations of the means $(\mathrm{n}=3)$ and different letters are significantly different $(\mathrm{p}<0.05)$

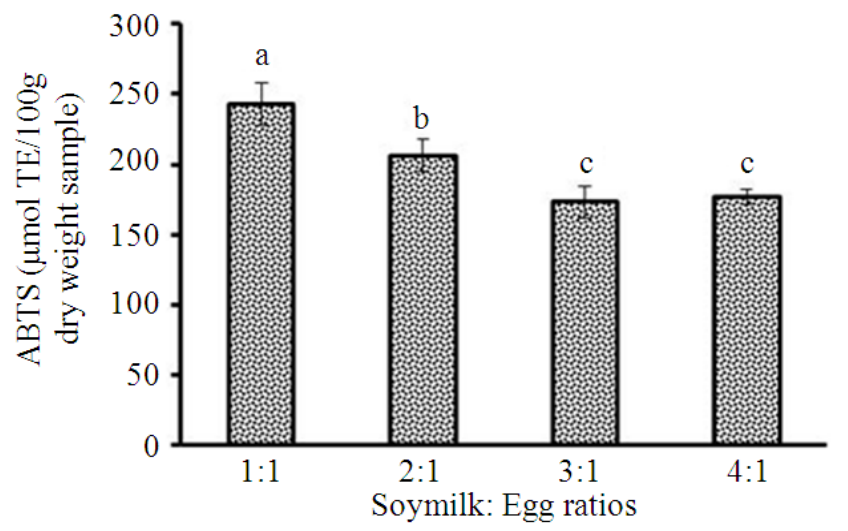

Fig. 3. Effect of soymilk and egg ratios on the antioxidant capacity of egg tofu in ABTS assay. Bars are the standard deviations of the means $(n=3)$ and different letters are significantly different $(\mathrm{p}<0.05)$

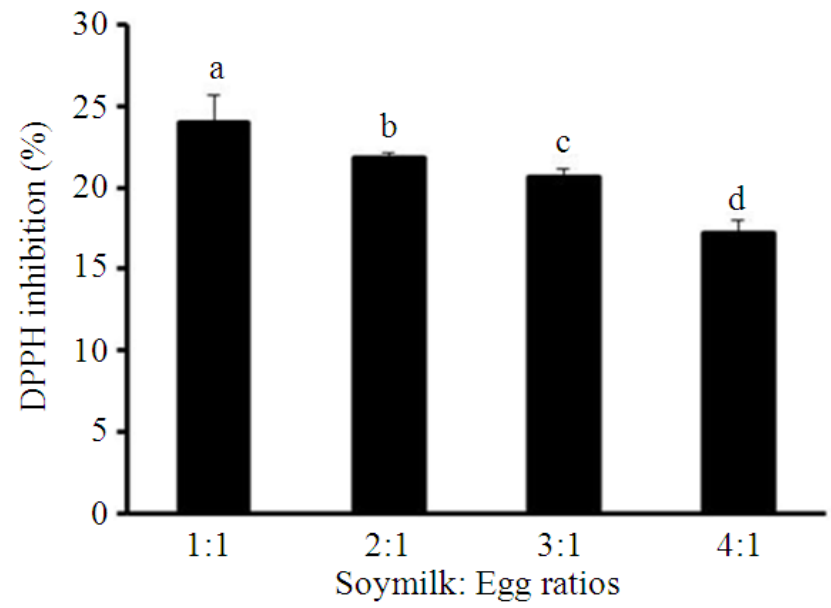

Fig. 4. Effect of soymilk and egg ratios on the antioxidant capacity of egg tofu in DPPH assay. Bars are the standard deviations of the means $(n=3)$ and different letters are significantly different $(\mathrm{p}<0.05)$ 


\subsection{Correlation}

The correlation coefficients between Total Phenolic Content (TPC), antioxidant capacity (FRAP, ABTS and $\mathrm{DPPH}$ ), daidzein, genistein and several amino acids are shown in Table 4. The TPC of egg tofu has a positive correlation and significant $(\mathrm{p}<0.01)$ with FRAP, daidzein and genistein with $\mathrm{r}$ value of $0.93,0.83$ and 0.72 respectively. This result was consistent with the obtained by Tyug et al. (2010) for soybean powder. In addition, FRAP had positive correlation and significant $(\mathrm{p}<0.01)$ with daidzein $(r=0.97)$ and genistein $(r=0.92)$.
Table 2. Effect of soy milk and egg ratios on the daidzein and genistein content of egg tofu

\begin{tabular}{lll}
\hline $\begin{array}{l}\text { Soymilk: } \\
\text { Egg ratio }\end{array}$ & $\begin{array}{l}\text { Daidzein }(\mathrm{mg} / 100 \mathrm{~g} \\
\text { dry weight sample) }\end{array}$ & $\begin{array}{l}\text { Genistein }(\mathrm{mg} / 100 \mathrm{~g} \\
\text { dry weight sample) }\end{array}$ \\
\hline $1: 1$ & $23.3 \pm 1.7^{\mathrm{d}}$ & $18.2 \pm 0.6^{\mathrm{d}}$ \\
$2: 1$ & $26.9 \pm 0.5^{\mathrm{c}}$ & $26.5 \pm 0.6^{\mathrm{c}}$ \\
$3: 1$ & $40.8 \pm 0.6^{\mathrm{b}}$ & $38.1 \pm 1.5^{\mathrm{b}}$ \\
$4: 1$ & $53.0 \pm 2.7^{\mathrm{a}}$ & $40.9 \pm 1.4^{\mathrm{a}}$ \\
\hline
\end{tabular}

a-d Mean value \pm standard deviation $(\mathrm{n}=3)$ in a column followed by different superscript letters are significantly different $(\mathrm{p}<0.05)$

Table 3. Effect of soymilk and egg ratios on the amino acid profiles of egg tofu ( $\mathrm{g} / 100 \mathrm{~g}$ sample)

Soymilk: Egg ratio of egg tofu

\begin{tabular}{|c|c|c|c|c|}
\hline Amino acids & $1: 1$ & $2: 1$ & $3: 1$ & $4: 1$ \\
\hline Asp & $1.01 \pm 0.08^{\mathrm{a}}$ & $0.95 \pm 0.04^{\mathrm{a}}$ & $0.95 \pm 0.06^{\mathrm{a}}$ & $1.07 \pm 0.10^{\mathrm{a}}$ \\
\hline Glu & $1.44 \pm 0.08^{\mathrm{a}}$ & $1.38 \pm 0.02^{\mathrm{a}}$ & $1.44 \pm 0.09^{\mathrm{a}}$ & $1.63 \pm 0.16^{\mathrm{a}}$ \\
\hline Ser & $0.76 \pm 0.01^{\mathrm{a}}$ & $0.65 \pm 0.00^{\mathrm{b}}$ & $0.65 \pm 0.00^{\mathrm{b}}$ & $0.70 \pm 0.04^{\mathrm{ab}}$ \\
\hline Gly & $0.39 \pm 0.01^{\mathrm{a}}$ & $0.38 \pm 0.03^{\mathrm{a}}$ & $0.39 \pm 0.02^{\mathrm{a}}$ & $0.43 \pm 0.04^{\mathrm{a}}$ \\
\hline His & $0.27 \pm 0.01^{\mathrm{a}}$ & $0.25 \pm 0.02^{\mathrm{a}}$ & $0.25 \pm 0.02^{\mathrm{a}}$ & $0.27 \pm 0.02^{\mathrm{a}}$ \\
\hline Arg & $0.76 \pm 0.02^{\mathrm{a}}$ & $0.71 \pm 0.02^{\mathrm{a}}$ & $0.74 \pm 0.05^{\mathrm{a}}$ & $0.82 \pm 0.07^{\mathrm{a}}$ \\
\hline Thr & $0.49 \pm 0.01^{\mathrm{a}}$ & $0.43 \pm 0.01^{\mathrm{a}}$ & $0.43 \pm 0.03^{\mathrm{a}}$ & $0.47 \pm 0.04^{\mathrm{a}}$ \\
\hline Ala & $0.55 \pm 0.02^{\mathrm{a}}$ & $0.49 \pm 0.01^{\mathrm{a}}$ & $0.48 \pm 0.03^{\mathrm{a}}$ & $0.52 \pm 0.05^{\mathrm{a}}$ \\
\hline Pro & $0.48 \pm 0.03^{\mathrm{a}}$ & $0.45 \pm 0.02^{\mathrm{a}}$ & $0.46 \pm 0.03^{\mathrm{a}}$ & $0.50 \pm 0.05^{\mathrm{a}}$ \\
\hline Tyr & $0.63 \pm 0.00^{\mathrm{a}}$ & $0.56 \pm 0.01^{\mathrm{a}}$ & $0.58 \pm 0.03^{\mathrm{a}}$ & $0.66 \pm 0.08^{\mathrm{a}}$ \\
\hline Val & $0.55 \pm 0.00^{\mathrm{a}}$ & $0.47 \pm 0.00^{\mathrm{b}}$ & $0.48 \pm 0.03^{\mathrm{b}}$ & $0.51 \pm 0.04^{\mathrm{ab}}$ \\
\hline Met & $0.27 \pm 0.01^{\mathrm{a}}$ & $0.21 \pm 0.01^{\mathrm{b}}$ & $0.17 \pm 0.00^{\mathrm{c}}$ & $0.15 \pm 0.00^{\mathrm{c}}$ \\
\hline Cys & $0.19 \pm 0.01^{\mathrm{a}}$ & $0.15 \pm 0.00^{\mathrm{b}}$ & $0.12 \pm 0.00^{\mathrm{c}}$ & $0.11 \pm 0.00^{\mathrm{c}}$ \\
\hline Ile & $0.48 \pm 0.01^{\mathrm{a}}$ & $0.45 \pm 0.04^{\mathrm{a}}$ & $0.43 \pm 0.03^{\mathrm{a}}$ & $0.47 \pm 0.06^{\mathrm{a}}$ \\
\hline Phe & $0.55 \pm 0.01^{\mathrm{a}}$ & $0.48 \pm 0.00^{\mathrm{a}}$ & $0.50 \pm 0.03^{\mathrm{a}}$ & $0.54 \pm 0.05^{\mathrm{a}}$ \\
\hline Lys & $0.72 \pm 0.03^{\mathrm{a}}$ & $0.63 \pm 0.00^{\mathrm{a}}$ & $0.64 \pm 0.05^{\mathrm{a}}$ & $0.70 \pm 0.07^{\mathrm{a}}$ \\
\hline Trp & $0.10 \pm 0.00^{\mathrm{a}}$ & $0.09 \pm 0.00^{\mathrm{b}}$ & $0.08 \pm 0.00^{\mathrm{bc}}$ & $0.08 \pm 0.00^{\mathrm{c}}$ \\
\hline Leu & $0.82 \pm 0.00^{\mathrm{a}}$ & $0.73 \pm 0.01^{\mathrm{a}}$ & $0.74 \pm 0.05^{\mathrm{a}}$ & $0.80 \pm 0.07^{\mathrm{a}}$ \\
\hline
\end{tabular}

${ }^{\mathrm{a}-\mathrm{c}}$ Mean value \pm standard deviation $(\mathrm{n}=2)$ in a raw followed by different superscript letters are significantly different $(\mathrm{p}<0.05)$

Table 4. Pearson's correlation coefficients for total phenolic content, antioxidant activities, daidzein, genistein and amino acids of egg tofu

\begin{tabular}{|c|c|c|c|c|c|c|c|c|c|c|c|c|}
\hline & TPC & FRAP & ABTS & DPPH & Daidzein & Genistein & Cys & Met & Tyr & Phe & His & Trp \\
\hline TPC & 1 & & & & & & & & & & & \\
\hline FRAP & $0.929 * *$ & 1 & & & & & & & & & & \\
\hline ABTS & $-0.574 *$ & $-0.790 * *$ & 1 & & & & & & & & & \\
\hline DPPH & $-0.830 * *$ & $-0.956^{* *}$ & $0.874 * *$ & 1 & & & & & & & & \\
\hline Daidzein & $0.831 * *$ & $0.974 * *$ & $-0.854 * *$ & $-0.964 * *$ & 1 & & & & & & & \\
\hline Genistein & $0.724 * *$ & $0.920 * *$ & $-0.898 * *$ & $-0.961 * *$ & $0.976^{* *}$ & 1 & & & & & & \\
\hline Cys & $-0.678^{*}$ & $-0.869 * *$ & $0.976^{* *}$ & $0.923 * *$ & $-0.942 * *$ & $-0.960 * *$ & 1 & & & & & \\
\hline Met & $-0.682 *$ & $-0.872 * *$ & $0.972 * *$ & $0.927 * *$ & $-0.946^{* *}$ & $-0.963 * *$ & $0.999 * *$ & 1 & & & & \\
\hline Tyr & -0.024 & $-0.258 *$ & $0.705^{*}$ & 0.430 & -0.420 & -0.515 & 0.627 & 0.624 & 1 & & & \\
\hline Phe & -0.261 & $-0.492 * *$ & $0.852 * *$ & $0.640 *$ & -0.627 & $-0.704^{*}$ & $0.810 * *$ & $0.807 * *$ & $0.955^{*} *$ & 1 & & \\
\hline His & -0.158 & $-0.386^{*}$ & $0.745^{*}$ & 0.522 & -0.534 & -0.611 & $0.700 *$ & $0.695 *$ & $0.929 * *$ & $0.929 * *$ & 1 & \\
\hline Trp & $-0.754 *$ & $-0.908 * *$ & $0.902 * *$ & $0.960 * *$ & $-0.959 * *$ & $-0.964 * *$ & $0.967 * *$ & $0.971 * *$ & 0.543 & $0.745^{*}$ & $0.659 *$ & 1 \\
\hline
\end{tabular}

**Correlation is significant at the 0.01 level.* Correlation of significant at the 0.05 level. Sis $=$ Cystein, Met $=$ Methionine,Tir $=$ Tyrosine, Fen $=$ Phenylalanine, His $=$ Histidine and $\operatorname{Trp}=$ Tryptophan 


\section{DISCUSSION}

Results showed that egg was the main contributor to the higher fat and protein content of egg tofu. However, there was no significant difference $(p>0.05)$ was observed for egg tofu with soymilk and egg ratios of $3: 1$ and 4:1 for moisture, fat and protein content.

Increased in soymilk ratio had increased in TPC of egg tofu. This could be attributed to the higher phenolic compounds present in soybean compared to egg. This results is in agreement with previous study which showed that soybean powder contained total phenolic content of $103.86 \mathrm{mg}$ of GAE/100 $\mathrm{g}$ of wet sample (Tyug et al., 2010) which is higher than egg yolk that merely contained $72.2 \mathrm{mg}$ of GAE/100 g of dry egg yolk (Nimalaratne et al., 2011).

Results showed that an increased in soymilk content had significantly $(p<0.05)$ increased the FRAP value at all soymilk and egg ratios. This indicated soymilk contain of antioxidant that had the ability to reduce ferric ion $\left(\mathrm{Fe}^{3+}\right)$ which is better compared to egg.

An increased in soymilk ratio up to $3: 1$, had decreased the antioxidant capacity (ABTS assay) of egg tofu significantly $(p<0.05)$. The result obtained was similar to previous research which showed antioxidant capacity of soymilk powder which is $10.1 \mu \mathrm{moL}$ TE/ $1 \mathrm{~g}$ wet weight (Tyug et al., 2010) was lower compared with capacity antioxidant in egg yolk which is $66.0 \mu \mathrm{mol}$ TE/1 g dry weight (Nimalaratne et al., 2011).

The highest TPC of egg tofu at soymilk and egg ratio $4: 1$, however had the lowest antioxidant capacity in DPPH assay. This is suggested that, phenolic compound in egg tofu did not contribute to the radical scavenging activity of DPPH. The most likely reason could be due to the presence of other compounds in the egg that contributed to the antioxidant activities of egg tofu such as amino acids which were found to have antioxidant activities. Amino acids such as cystein, methionine, tyrosine, tryptophan, phenylalanine and histidine in peptides from egg white lysozime and tyrosine and tryptophan in egg yolk are the main contributors to the antioxidant activities (Nimalaratne et al., 2011; You et al., 2010).

The higher ratio of soymilk had increased in daidzein and genistein content of egg tofu. Daidzein concentration in soy tofu was in the range of 39-114 mg/100 $\mathrm{g}$ dried weight and genistein was in the ranged of 38-147 mg/100 g dried weight (Hui et al., 2001) which was higher compared to egg tofu as stated by Hasnah et al. (2009).

Increased in soymilk ratio had significantly decreased in amino acids methionine (met) and cystein (cys) in egg tofu. This is because egg contained methionine and cysteine which is higher compared to soymilk (Shurtleff and Aoyagi 2001). Therefore, egg tofu at all ratios of soymilk and egg produced contained higher amino acids content compared to those regular soy tofu reported by Kim et al. (2009).

Generally, TPC was positively correlated with the percentage of DPPH inhibition (Maizura et al., 2011). However, the result showed that the TPC has a strong negative correlation $(\mathrm{p}<0.01)$ with percentage of DPPH inhibition $(\mathrm{r}=-0.83)$. The higher DPPH inhibition could be caused by several amino acids that contributed to the antioxidant activities, as evidenced by the strong positive correlation $(p<0.01)$ between percentage of DPPH inhibition with cystein, methionine and tryptophan with $r$ value of $0.92,0.93$ and 0.96 respectively. There was positive correlation and significant $(\mathrm{p}<0.01)$ between ABTS and DPPH $(r=0.87)$.

\section{CONCLUSION}

An increased in the soymilk content had significantly $(p<0.05)$ enhanced the total phenolic content and FRAP values. However, had resulted in the decreased of radical scavenging activities of ABTS and DPPH. Egg tofu with higher ratios of soymilk contained higher daidzein and genistein as well as amino acid methionine and cysteine. Amino acids such as cystein, methionine, tryptophan, phenylalanine, histidine and tryptophan had showed positive correlation and significant $(\mathrm{p}<0.05)$ with radical scavenging activity of ABTS.

\section{ACKNOWLEDGEMENT}

The researchers would like to express their gratitude to Universiti Kebangsaan Malaysia for their financial support (UKM-GUP grant-NBT-08-27-103 and UKMOUP grant-NBT-27-133/2) for this research as well as Universiti Sains Malaysia for the financial support for the first author.

\section{REFERENCES}

Akowuah, G.A., Z. Ismail, I. Norhayati and Sadikun, 2005. The effects of different extraction solvents of varying polarities of polyphenols of Orthosiphon stamineus and evaluation of the free radicalscavenging activity. J. Food Chem., 93: 311-317. DOI: $10.1016 /$ j.foodchem.2004.09.028

AOAC, 2000. Official Methods of Analysis of the AOAC. 17th Edn., Association of Official Analytical Chemists, Arlington, Va., ISBN-10: 0935584242. 
Arzeni, C., E.P. Oscar and A.M.R. Pilosof, 2012. Functionality of egg white proteins as affected by high intensity ultrasound. Food Hydrocolloids, 29: 308-316. DOI: 10.1016/j.foodchem.1202.03.009

Benzie, I.F.F. and J.J. Strain, 1996. The Ferric Reducing Ability of Plasma (FRAP) as a measure of "antioxidant power" the FRAP assay. Anal. Biochem., 239: 70-76. PMID: 8660627

Binsan, W., S. Benjakul, W. Visessanguan, S. Roytrakul and M. Tanaka et al., 2008. Antioxidative activity of Mungoong, an extract paste, from the cephalothorax of white shrimp (Litopenaeus vannamei). J. Food Chem., 106: 185-193. DOI: 10.1016/j.foodchem.2007.05.065

Bouayed, J. and T. Bohn, 2010. Exogenous antioxidantsdouble-edged swords in cellular redox state. Oxid. Med. Cell Longev., 3: 228-237. DOI: 10.4161/oxim.3.4.12858

Daimer, K. and U. Kulozik, 2009. Oil-in-water emulsion properties of egg yolk: Effect of enzymatic modification by phospholipase A2. J. Food Hydrocolloids, 23: 1366-1373. $\quad$ DOI: 10.1016/j.foodhyd.2008.10.002

Dia, V.P., W. Wanga, V.L. Oh, B.O.de Lumen and E. Gonzalez de Mejia, 2009. Isolation, purification and characterisation of lunasin from defatted soybean flour and in vitro evaluation of its anti-inflammatory activity. Food Chem., 114: 108-115. DOI: 10.1016/j.foodchem.2008.09.023

Duenas, M., H. Teresa, R. Sergio, L. Grzegorz, E. Isabel, R. Munoz. 2012. Bioactive phenolic compounds of soybean (Glycine max cv. Merit): Modifications by different microbiological fermentation. Pol. J. Food Nutr. Sci., 62: 241-250. DOI: 10.2478/v10222-0120060-X

Dwiecki, K., G. Neunert, P. Polewski and K. Polewski, 2009. Antioxidant activity of daidzein, a natural antioxidant and its spectroscopic properties in organic solvents and phosphatidylcholine liposomes. J. Photochem. Photobiol. B: Biol., 96: 242-248. PMID: 19648024

Hasnah, H., I. Amin, A. Azrina, S.Suzana and S.P. Loh, 2009. Daidzein and genestein contents in tempeh and selected soy products. Food Chem., 115: 13501356. DOI: 10.1016/j.foodchem.2009.01.053

Hui, E., S.M. Henning, N. Park, D. Heber and W.G. Vay Liang, 2001. Genistein and daidzein/glycitein content in tofu. J. Food Compos. Anal., 14: 199-206. DOI: 10.1006/jfca.2000.0941

Kim, B.H., H.S. Lee, Y.A. Jang, J.Y. Lee and Y.J. Cho et al., 2009. Development of amino acid composition database for Korean foods. J. Food Compos. Anal., 22: 44-52. DOI: 10.1016/j.jfca.2008.07.005
Kim, D.O. and C.Y. Lee, 2000. Extraction and Isolation of Polyphenolics. In: Current Protocols in Food Analytical Chemistry, Wrolstad, R.E. (Ed.), John Wiley and Sons, New York, ISBN-10: 0471325651, pp: $1-12$.

Maizura, M., A. Aminah and W.M.W. Aida, 2011. Total phenolic content and antioxidant activity of kesum (Polygonum minus), ginger (Zingiber officinale) and turmeric (Curcuma longa) extract. Int. Food Res. J., 18: 529-534.

Medoua, G.N., A.A. Egal and W.H. Oldewage-Theron, 2009. Nutritonal value and antioxidant capacity of lunch meals consumed by elderly people of Sharpeville, South Africa. Food Chem., 115: 260264. DOI: 10.1016/j.foodchem.2008.12.007

Nimalaratne, C., D. Lopes-Lutz, A. Schieber and J. Wu, 2011. Free aromatic amino acids in egg yolk show antioxidant properties. Food Chem., 129: 155-161. DOI: 10.1016/j.foodchem.2011.04.058

Rock, L., S. Rowe, A. Czerwiec and H. Richmond, 2013. Isotopic analysis of eggs: Evaluating sample collection and preparation. Food Chem., 136: 15511556. PMID: 23194561

Shao, S., A.M. Duncan, R. Yang, M.F. Marcone and I. Rajcan et al., 2009. Tracking isoflavones: From soybean to soy flour, soy protein isolates to functional soy bread. J. Functional Food, 1: 119127. DOI: $10.1016 /$ j.jff.2008.09.013

Shurtleff, W. and A. Aoyagi, 2001. Tofu and Soymilk Production. 3rd Edn., Soyfoods Center, Lafayette, CA., ISBN-10: 1928914047, pp: 336.

Singleton, V.L. and J.A. Rossi, 1965. Colorimetry of total phenolics with phosphomolybdicphosphotungstic acid reagents. Am. J. Enol. Viticul., 16: 144-158.

Song, F.L., R.Y. Gan, Y. Zhang, Q. Xiao and L. Kuang et al., 2010. Total phenolic contents and antioxidant capacities of selected Chinese medicinal plants. Int. J. Mol. Sci., 11: 2362-2372. DOI: 10.3390/ijms 11062362

Tang, D.W., S.H. Yu, Y.C. Ho, B.Q. Huang, G.J. Tsai, H.Y. Hsieh et al., 2013. Characterization of tea catechins-loaded nanoparticles prepared from chitosan and an edible polypeptide. Food Hydrocolloids, 30: 33-41. DOI: 10.1016/j.foodhyd.2012.04.014

Tyug, T.S., K.N. Prasad and A. Ismail, 2010. Antioxidant capacity, phenolics and isoflavones in soybean by-products. Food Chem., 123: 583-589. DOI: $10.1016 /$ j.foodchem.2010.04.074

WCD, 1993. Waters AccQ.Tag Amino Acid Analysis System. 1st Edn., Millipore Corporation, Milford, USA., pp: 19. 
Maizura Murad et al. / American Journal of Applied Sciences 10 (11): 1315-1324, 2013

Walker, L. A., T. Wang, H. Xin and D. Dolde, 2012. Supplementation of laying-hen feed with palm tocos and algae astaxanthin for egg yolk nutrient enrichment. J. Agric. Food Chem., 60: 1989-1999. DOI: $10.1021 /$ jf204763f
You, S.J., C.C. Udenigwe, R.E. Aluko and J. Wua, 2010. Multifunctional peptides from egg white lysozyme. Food Res. Int., 43: 848-855. DOI: 10.1016/j.foodres.2009.12.004 